\title{
Using methane clumped isotopes to investigate thermal generation of Longmaxi shale gas in Sichuan Basin, \\ China
}

${ }^{*}$ CHENGSHENG CHEN ${ }^{1,2,4}$, YUNPENG WANG ${ }^{1}$, GREG

HOLLAND $^{3}$, ZHENG ZHOU ${ }^{2}$

${ }^{1}$ SKLOG, Guangzhou Institute of Geochemistry, Chinese Acadamy of Sciences, China. chenc26@lancaster.ac.uk

(*presenting author); wangyp@gig.ac.cn

${ }^{2}$ Lancaster Environmental Centre, Lancaster University, UK. z.zhou4@lancaster.ac.uk

${ }^{3}$ Department of Earth and Environmental Sciences, The University of Manchester, UK. g.holland@manchester.ac.uk

${ }^{4}$ University of Chinese Academy of Sciences, Beijing, China

Methane clumped isotopes have been used to reconstruct formation temperatures of natural gases at which methane was formed or thermally equilibrated. However, due to analytical challenges and complexity in data interpretation, application of this technique is still at the early stage. In this study, we aim to present methane clumped isotope data $\left({ }^{13} \mathrm{CH}_{3} \mathrm{D}\right)$ for samples from Fuling shale gas field in Sichuan Basin (China) and compare the clumped signature with both $\mathrm{C}$ and $\mathrm{H}$ isotopes and our basin modelling results.

Eight gas samples were collected from the black shale Longmaxi Formation in the Fuling area and analysed for major composition and carbon isotopes. Basin modelling was then conducted to obtain the burial and thermal history of target shales. Methane clumped isotopes are currently being measured by using tunable infrared laser direct absorption spectroscopy (TILDAS) at Lancaster Environment Centre. Existing data show that methane in samples accounts for $97.2 \%$ to $98.4 \%$ of the total gas, and $\delta^{13} \mathrm{C}$ varies between $-28.3 \%$ to $-31.0 \%$, implying its origin may be consistent with the thermal generation. Basin modelling results suggest that shales reached the maximum formation temperature $\left(>200^{\circ} \mathrm{C}\right)$ during the largest deposition event in late Cretaceous, and therefore methane was formed above the oil window. Later, shales were uplifted and cooled to current low temperature. Formation temperatures calculated by methane clumped isotopes will be compared with constraints from basin modelling, and are expected to confirm the thermal generation history of the gases.

Combined geochemical and modelling approaches show that gases in Longmaxi formation are thermogenic and non-associated gases, which were formed when shales reached maximum burial depth in late Cretaceous. We are working to develop the methane clumped isotope TILDAS technique and demonstrate that methane clumped isotopes can be applied together with basin modelling to unlock critical information for constraining the source of methane in basin studies. 